\title{
The role of community pharmacists and their position in the delivery of diabetes care: an update for medical professionals
}

\author{
Sarah Brewster (10, ${ }^{1}$ Richard Holt, ${ }^{2}$ Jane Portlock, ${ }^{3}$ Hermione Price ${ }^{1}$
}

- Additional material is published online only. To view please visit the journal online (http://dx.doi.org/10.1136/ postgradmedj-2020-137511).

${ }^{1}$ Research and Development, Southern Health NHS

Foundation Trust,

Southampton, UK

${ }^{2}$ Division of Human Development and Health, University of Southampton, Southampton, UK

${ }^{3}$ School of Life Sciences, University of Sussex, Brighton, UK

Correspondence to Dr Sarah Brewster, Research and Development, Southern Health NHS Foundation Trust, Southampton SO40 8DX, UK; sarah.brewster@doctors.org.uk

Received 14 January 2020 Revised 3 March 2020 Accepted 6 March 2020
Check for updates

(C) Author(s) (or their employer(s)) 2020. No commercial re-use. See rights and permissions. Published by BMJ.

To cite: Brewster $S$, Holt R, Portlock J, et al. Postgrad Med J 2020;96:473-479.

\section{ABSTRACT}

Pharmacists are the third largest group of healthcare professionals worldwide, but are underused in the delivery of diabetes care. The aim of this narrative was to describe how integration of community pharmacy services into existing healthcare models may improve diabetes care. Relevant literature exploring pharmacy-led interventions for diabetes were identified from a search of Medline, Embase and Cinahl online databases. This review highlights that community pharmacists are accessible, experts in medicine management, trusted by the public and able to achieve financial savings. They are poorly integrated into existing healthcare models, and commissioning arrangements can be poorly perceived by the public and those working in primary care. Community pharmacy interventions in type 2 diabetes have similar, if not greater effects compared to those delivered by other healthcare professionals. It was concluded that community pharmacy interventions in diabetes are feasible, acceptable and deliver improved health outcomes. Future work should build public recognition of pharmacists and improve communication between them and other healthcare professionals.

\section{INTRODUCTION AND BACKGROUND}

Diabetes is one of the most prevalent chronic conditions and is associated with significant disability, morbidity and mortality. Worldwide, the number of adults living with the condition is projected to increase by more than $50 \%$ from 463 million to 700 million by $2040 .{ }^{1}$ The implications this has on healthcare services are considerable. ${ }^{2}$ Approximately US $\$ 760$ billion is spent per annum on diabetes care, representing $10 \%$ of the global healthcare budget.

In order to minimise the long-term risk of both microvascular and macrovascular complications, individuals with diabetes are advised to follow a number of self-care practices which can be both demanding and challenging. ${ }^{3}$ In most countries, people with diabetes are offered support from a multidisciplinary team of healthcare professionals. Pharmacists are highly skilled and comprise the third largest group of healthcare professionals, but to date, are a largely untapped resource in the delivery of diabetes care worldwide. ${ }^{4}$ With the growing number of people living with diabetes and the increasing strain on healthcare services, pharmacists are well situated to offer collaborative and complementary expertise alongside current models of care. $^{45}$

\section{AIM}

The aim of this narrative review is to familiarise medical professionals with the expanding role of community pharmacists, and to explore the potential for their improved integration in the delivery of diabetes care and its associated services. We will summarise the literature on the impact of pharmacyled interventions in diabetes. Although we have given a global perspective where possible, we have used the UK to illustrate the facilitators and barriers to the involvement of community pharmacists.

\section{METHODS}

To provide a summary of the evolving pharmacy profession and services, their strengths and the challenges limiting increased interoperability with other healthcare services, published data from key organisations and stakeholders were reviewed. This included, but was not limited to, the International Pharmacy Federation, the Royal Pharmaceutical Services, the Pharmaceutical Services Negotiating Committee, National Health Service (NHS) England, the National Institute for Health and Care Excellence and the Kings Fund.

To explore the literature on pharmacy-led diabetes interventions, an online search was carried out using three databases: Medline, Embase and Cinahl, from the date of database inception until September 2019. Searches were restricted to English language. The following search strategy was used:

Diabet" adj1 (type one or type two or "insulin dependent" or type two or type two or "non-insulin dependent")

and

Pharmac* adj1 (care or clinical or community or service*) or exp pharmaceutical services/ and

Education or "self-management" or "self-care" or intervention or "medication management" or Knowledge or "glycosylated or glycated haemoglobin" or "HbA1c" or "behaviour change" or "behaviour change" or "glycaemic control" or "glycemic control"

\section{INTRODUCTION TO PHARMACY}

\section{Pharmacists and the pharmacy workforce}

Globally there are over 2 million licensed or registered pharmacists, equivalent to 5 pharmacists per 10000 population. Access to pharmacy services, however, varies widely between low-income and high-income countries with 8.28 pharmacists per 10000 population in Europe compared with 0.61 
in Africa. ${ }^{6}$ Pharmacists work across a variety of settings including hospitals, general practice, outpatients, industry, the military and prisons, but the majority $(70 \%)$ are based in community pharmacies. $^{6} 7$

Pharmacy training differs across the world, but typically comprises a 4-year Master of Pharmacy undergraduate degree followed by a preregistration year. ${ }^{4}$ Once registered, pharmacists may undergo further training to become more specialised and/or independent prescribers. ${ }^{8}$

Other important members of the community pharmacy workforce include pharmacy technicians and pharmacy assistants who work alongside and under the supervision of licensed pharmacists.

\section{Commissioning of community pharmacy services}

Rapid changes are occurring globally in how community pharmacies are remunerated, with less focus on dispensing and more focus on clinical services. ${ }^{9}$ Payment methods and fees for pharmacy services vary widely across countries and between districts. Some services are reimbursed by government agencies or insurance plans while in other settings, services are paid directly by patients or funded by academic institutions. Regardless of the mechanism of payment, there has been a gradual shift towards quality-based reimbursement and less opportunity for business autonomy. For example, in England, where community pharmacies provide their services under the Community Pharmacy Contractual Framework, all pharmacies must demonstrate that they actively promote health and well-being, and through a structured framework, provide a breadth of public health services to empower people to self-manage their health. ${ }^{10}$ Extra funding is available for pharmacists to undertake additional work. ${ }^{10}$ Although this changes annually, for 2019/2020, checking that people with diabetes have had their annual foot check and retinal screening is one of the optional requirements to acquire additional revenue.

\section{STRENGTHS OF COMMUNITY PHARMACISTS Trust and accessibility}

Pharmacists are one of the most trusted professions worldwide alongside firefighters, nurses, teachers and doctors. ${ }^{11}$ Different cultural, religious and socioeconomic backgrounds are represented by the pharmacy workforce, and this wealth of diversity potentially minimises the impact of any language or cultural barriers that may impact healthcare delivery. ${ }^{8}$

Pharmacists are the most accessible healthcare provider in many parts of the world, and this access is typically greatest in areas of highest deprivation-the 'positive pharmacy care law'. ${ }^{12}$ In the UK, the majority of the population has a pharmacy within a 20 min walk from their household. ${ }^{13}$ Pharmacies have longer working hours than many other healthcare facilities and are accessible without registration, therefore offer a degree of anonymity, alongside a flexible, informal environment. ${ }^{4}$ Ninety per cent of community pharmacies in England have private consultation rooms which makes them well equipped for more confidential discussions and services. ${ }^{4}$

In England, adults visit a pharmacy on average 16 times a year, and those with diabetes are known to visit their pharmacist three to eight times more frequently than those without diabetes. ${ }^{14} 15$ There are 1.2 million health-related visits each day across the 11700 community pharmacies in England. ${ }^{4}$ This frequency of access makes pharmacists well placed to recognise the early signs and symptoms of long-term conditions including diabetes, as well as helping to prevent these conditions and their associated complications.

\section{Improving concordance with prescribed medication/ understanding prescribed medication}

NHS England has recognised systematic support from community pharmacists in medication taking as a 'high value intervention' for the reduction of cardiovascular disease in people living with diabetes. ${ }^{16}$ Taking medication as prescribed correlates with positive health outcomes while not taking medication is associated with therapeutic failure, hospitalisation and disease progression. ${ }^{17}$ Between 30\% and 50\% of the medicines prescribed for long-term conditions are not taken correctly, and this is where pharmacy interventions have been of particular benefit. ${ }^{18}$

The second Diabetes Attitudes, Wishes and Needs Study in 2012 was the largest global psychosocial diabetes survey of its kind. It explored the perceptions and attitudes of more than 8000 people with diabetes, 2000 family members as well as nearly 5000 healthcare professionals across 17 countries. ${ }^{19}$ The study revealed that more than a third of people with diabetes felt that their medication interfered with their life and that their treatment regimen was too complicated. Pharmacists are skilled at performing medication reviews, and their expertise is well suited to supporting people who are having difficulties with their treatment regimen. More than 55\% of people with diabetes are worried about the risk of hypoglycaemia. ${ }^{19}$ Pharmacists can provide individual education and advice on how to minimise this risk.

Better support and lower disease burden, in terms of complications, are both associated with more favourable outcomes with respect to well-being and quality of life. ${ }^{19}$ Community pharmacists can provide additional support to what already takes place in existing diabetes healthcare services, and in doing so, help to reduce disease burden.

\section{Scope for development of more integrated working}

Globally, pharmacists are assuming more active clinical positions within interprofessional healthcare teams. ${ }^{9}$ Their roles are expanding from traditional dispensing to include more comprehensive clinical services. ${ }^{69}$ Specialist pharmacy services are now being offered in more than $50 \%$ of countries and territories and include disease management programmes, clinical measurements and medicine usage reviews. ${ }^{6}$ Pharmacists have also begun to integrate with primary care practices in England, and by 2020/ 2021, NHS England has made a commitment to have one pharmacist embedded in general practice for every 30000 of the population. ${ }^{4}$

The International Pharmaceutical Federation envisages a future of common patient databases and shared care protocols across care settings, developed collaboratively and based on best evidence. ${ }^{9}$ Digital integration is important for this and for pharmacy services to become better embedded into healthcare models, but is still limited in most countries. ${ }^{6}$

\section{Financial sustainability}

Considerable cost savings can be achieved globally, across a breadth of settings by increased delivery of additional services in community pharmacy. ${ }^{20} \mathrm{An}$ independent report demonstrated that community pharmacy in England contributed an in-year benefit of $£ 3$ billion in 2015 , with a further $£ 1.9$ billion expected to accrue over the next 20 years. ${ }^{21}$ More work is required to understand which pharmacy services have the most substantive clinical benefits to patients while also delivering cost savings for healthcare budgets worldwide. ${ }^{20}$ 


\section{OPPORTUNITIES FOR COMMUNITY PHARMACISTS IN DIABETES CARE}

Government policies are beginning to recognise the value of community pharmacists in supporting the management of people with long-term conditions such as diabetes. ${ }^{9}$ The frequent contact the public has with pharmacists is unique and this contact is greatest in those with long-term conditions, notably diabetes. The management of diabetes is complex, relying on a number of selfcare practices. ${ }^{3}$ These include, but are not limited to, careful attention to lifestyle including diet, regularly attending healthcare appointments, taking medication(s) and, in some instances, having to regularly measure blood glucose and inject insulin.

Empowerment is key to enabling people with diabetes to manage their condition and to adapt to various life circumstances. ${ }^{22}$ For some, this journey can be more challenging. A healthcare appointment may not coincide with when an individual most needs help or support, and there are several reasons why an individual with diabetes may become 'hardly reached'. It has been well described that 'hardly reached' individuals are at increased risk of diabetes-related complications. ${ }^{23}$

The Royal Pharmaceutical Society has stated that pharmacists should be supported to play a greater role in the psychological and emotional support of those living with diabetes. ${ }^{8}$ With their increased availability, accessibility and informal set-up, pharmacists have the potential to be there for individuals when they are most at need. With appropriate training, they are well positioned to notice 'red flags' such as acute foot problems, frequent hypoglycaemia, diabetes distress and to refer to appropriate services if needed, while offering an alternative means of identifying and reaching out to people who are struggling.

\section{COMMUNITY PHARMACY INTERVENTIONS IN DIABETES}

Community pharmacy interventions have been trialled across a breadth of healthcare settings, covering a variety of chronic health conditions including asthma, ${ }^{24}$ chronic obstructive pulmonary disease ${ }^{25}$ and cardiovascular disease. ${ }^{26}$ There is an expanding body of evidence supporting the role of community pharmacists in the delivery of diabetes care (online supplemen tary tables 1 and 2). Despite varied settings, healthcare models and population groups, several systematic reviews have demonstrated the favourable impact community pharmacy interventions have on both clinical and patient-related outcomes (online supplementary table 2). ${ }^{27-35}$

Compared with diabetes interventions led by other healthcare professionals, those run by pharmacists have delivered at least comparable effectiveness in terms of lowering glycated haemoglobin $\left(\mathrm{HbA}_{1 \mathrm{c}}\right)$, and improving cardiovascular risk factors, self-management and medication taking. ${ }^{33}$ 35-37 Furthermore, improvements in $\mathrm{HbA}_{1 \mathrm{c}}$ are not always influenced by starting $\mathrm{HbA}_{1 \mathrm{c}}$ or the age of the participant. ${ }^{38}$

\section{Interventions for type 2 diabetes}

A significant majority of studies evaluating the effectiveness of pharmacy-delivered interventions for diabetes have focused on type 2 diabetes. The duration of interventions has typically ranged from 3 months to 12 months, while the follow-up period has ranged from 1 month to 4 years. ${ }^{35} 37$ There is conflicting evidence as to whether duration predicts effect ${ }^{323435}$ but it has been proposed that frequency of contact is most important. ${ }^{39}$

The outcomes measured in diabetes pharmacy interventions worldwide have been varied and not always standardised, making interpretation of findings complex. Outcome measures have included $\mathrm{HbA}_{1 \mathrm{c}}$, fasting glucose, self-measurement of blood glucose, blood lipids, body mass index, blood pressure, measures of diabetes self-care, medication adherence, diet, exercise and foot care. ${ }^{40}$ Meta-analyses have found that interventions that combine diabetes education with pharmacy care have the greatest impact across a variety of health outcomes. ${ }^{35} 37$ Although positive effects have been demonstrated across health outcomes, a network metaanalysis of pharmacy-delivered education interventions confirmed both clinically and statistically significant positive effects on $\mathrm{HbA}_{1 \mathrm{c}}$, body mass index, blood pressure and lipid profiles. ${ }^{37}$

A majority of pharmacy-delivered interventions to date have been reliant on face-to-face consultations with a pharmacist with a median duration of 45 min. ${ }^{32}$ Although most intervention elements have demonstrated a significantly positive affect on $\mathrm{HbA}_{1 \mathrm{c}}$, the most effective of these have been patient-centred and personalised and involved working across disciplines. ${ }^{32}$ Goal setting and sending feedback or recommendations to the general practitioner (GP) had the greatest effect in a systematic review; however, the details of the interventions are often poorly described, making translation of these findings into clinical practice in other settings challenging. ${ }^{32}$

Intervention components that included reviewing blood glucose data helped empower people with diabetes, but the measurements and assessments that had the most notable influence on $\mathrm{HbA}_{1 \mathrm{c}}$ were those assessing current health status, patient health beliefs and current medication knowledge. ${ }^{32}$

When considering patient-related outcome measures, pharmacy interventions have achieved statistically significant improvements in the quality of life for those living with type 2 diabetes, in part, by increasing diabetes knowledge and reducing concerns about diabetes medications. ${ }^{14} 41$ Although the evidence is limited, community pharmacists have also shown that they are capable of providing a breadth of foot care interventions to people with diabetes, resulting in improved foot outcomes. ${ }^{42}$

While most interventions have focused on the individual with diabetes, family based interventions by pharmacists for type 2 diabetes have also exhibited statistically significant reductions in $\mathrm{HbA}_{1 \mathrm{c}}$, blood pressure and blood lipids. ${ }^{43}$ This was most notable when the family member was a female caregiver or wife.

The training pharmacists receive for diabetes interventions differs significantly in duration between studies, with a median of 13 hours. ${ }^{32}$ Topics covered during this training have typically consisted of information on the pathophysiology, diagnosis and treatment of diabetes, lifestyle advice and practical aspects of diabetes self-management. ${ }^{32}$ There is large variation in the content and delivery of diabetes pharmacy interventions, ${ }^{37} 39$ and while it is clear that a majority have had favourable effects, the granularity of their component parts are often poorly described, making it difficult to define the active and reproducible constituents. $^{37}$

\section{Interventions for type 1 diabetes}

Although the evidence for interventions specific to type 1 diabetes is less well published, those that have been done have proven effective. ${ }^{44}{ }^{45}$ When tailored to adolescents with type 1 diabetes and elevated $\mathrm{HbA}_{1 \mathrm{c}}$, Obarcanin et al demonstrated that a multidisciplinary pharmacy care intervention could improve quality of life and $\mathrm{HbA}_{1 \mathrm{c}}$ without increasing the frequency of hypoglycaemia. ${ }^{44}$ The 6 -month intervention included monthly 60-90 min scheduled visits with a pharmacist. Clinical data were recorded and assessments made to identify any problems or drugrelated needs. Care plans were drawn up with the individual to incorporate at least one measurable goal and one problemsolving task. The participant's physician was kept informed and 


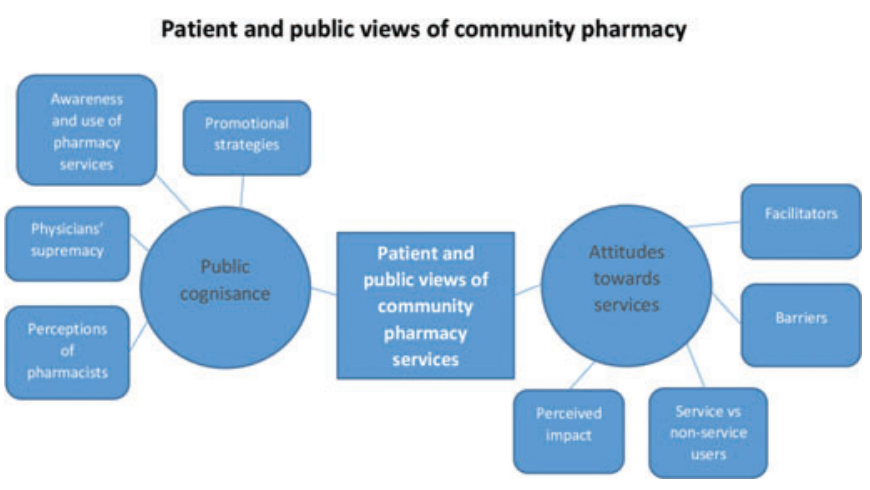

Figure 1 Thematic map of themes explaining patient and public perception of pharmacists (adapted from Hindi et al). ${ }^{53}$

helped oversee the intervention. The effect was most noticeable after 3 months.

\section{Telemedicine interventions}

Telemedicine has proven to be feasible in the delivery of diabetes care, with modest benefit in lowering $\mathrm{HbA}_{1 \mathrm{c}}$ and improving other clinical outcomes with greater sustainability over time in comparison to usual care. ${ }^{46}{ }^{47}$ Multidisciplinary telemedicine clinics including pharmacists have helped reach people with diabetes in more rural areas to good effect. ${ }^{47}$

Lauffenburger et al trialled a behavioural pharmacist telephone intervention aimed at improving glycaemic control in those with an $\mathrm{HbA}_{1 \mathrm{c}}$ of $>64 \mathrm{mmol} / \mathrm{mol}(>8 \%) .{ }^{48}$ The pharmacists used brief negotiated interviewing and shared decision making to identify and set patient goals. The goals focused on either treatment intensification or addressing lifestyle factors. There was a significant reduction in $\mathrm{HbA}_{1 \mathrm{c}}$ when measuring 'as treated', but not when measuring 'intention to treat'. Only $30 \%$ or those approached accepted the initial pharmacist telephone consultation and $25 \%$ of participants were not ready to change the way they managed their diabetes. It was felt that a more thorough assessment of the participants' perceived or real barriers to disease management would have strengthened the intervention. The authors described the difficulty in delivering the intervention in the context of multiple comorbidities. Other trials piloting pharmacy telephone interventions in diabetes care are in progress. $^{49}$

\section{Limitations of published studies}

Pharmacy-based interventions are complex health endeavours that include a number of interactive and influencing factors, many of which cannot be measured. This complexity makes it difficult to pinpoint the active and reproducible ingredients contributing to an effect, or lack thereof.

A number of randomised controlled trials demonstrate a sizeable risk of bias when they have been assessed for quality. This has largely been a result of the randomisation process and deviation from the intended intervention due to lack of blinding of participants. ${ }^{32} 35$ Nonetheless, there is consistency across studies showing that community pharmacy interventions are capable of offering an additional strategy and skill set in the delivery of diabetes care which often leads to improved healthcare outcomes for those enrolled.

\section{BARRIERS TO COMMUNITY PHARMACY The Murray report}

An independent review of community pharmacy clinical services in England published in 2016 by the Kings Fund, the Murray report, highlighted that renewed efforts should be made to make the most of the existing clinical services provided by pharmacists, particularly as the uptake of these had been poor. ${ }^{50} 51$ Three key thematic barriers were identified as contributing to the low uptake of the clinical services delivered by pharmacists. First, poor integration with other parts of the NHS, largely as a result of the limited capability of available digital platforms. Second, culture and behavioural issues in primary care around the role and identity of pharmacists, significantly slowing the mobilisation of the profession into healthcare models. Lastly, complex system designs including pharmacy contracts and commissioning routes are poorly understood, further disadvantaging the involvement of community pharmacy in the negotiation of evolving care models and more integrated working. ${ }^{5051}$ These barriers are not unique to England and have been described in other countries. $^{652}$

\section{The public perception of community pharmacy services}

A systematic review by Hindi et al exploring patient and public perspectives of community pharmacies in the UK identified two main themes, each of which had four subthemes (figure 1). ${ }^{53}$ Public cognisance was used to describe the opinions and views of the public. These were influenced by four factors: awareness of the pharmacy services available, underlying perceptions, whether the public regarded physicians to have a supremacy and promotional strategies encountered.

There was a general unfamiliarity of the local pharmacy services available, which qualitative work attributed to limited publicity of services. ${ }^{53}$ Perceptions of pharmacists were highest for activities linked to their traditional roles relating to medicines such as medicine reviews and advice, but lower for other services. Some studies reported public suspicion over the pharmacy commercial affiliations and financial incentives. The public's perception of their physician also had an influence on their confidence with pharmacists. Good relations with the physician reduced the need to consult the pharmacist and vice versa. Some believed that a pharmacist's advice needed confirmation by a physician. Publicity was generally lacking, but few studies commented on how this could be improved. Word of mouth was deemed to be most effective in a questionnaire, but focus group discussions did not reveal a preferable approach.

The public's attitudes towards pharmacy services was the second main theme. It depended on the perceived impact of pharmacy services, whether the individual had made use of them before and any barriers and/or facilitators to using pharmacy services. Facilitators included pharmacists' professionalism, ease of access and convenience, not needing an appointment, and feeling more comfortable and relaxed than with a physician. Barriers included lack of privacy, lack of access to medical records, inability to prescribe, poor communication with other healthcare providers, lack of continuity and limited pharmacist time. A significant proportion of the public did not know about the private consultation rooms available in many pharmacies, or if they did, had associated them with being used for substance misuse services.

Later focus group work by Hindi et al in 2019 explored the experiences and expectations of patients, pharmacists and GPs on the integration of community pharmacy into the primary care pathway for people with long-term conditions. ${ }^{54}$ Increased 
Main messages

- People with diabetes are offered support from a multidisciplinary team of healthcare professionals, but community pharmacists are often overlooked.

- Diabetes pharmacy interventions deliver favourable outcomes, comparable in their effect to those delivered by other healthcare professionals.

- Some of the barriers to the incorporation of community pharmacy into diabetes healthcare models have included poorly integrated digital platforms, limited recognition of pharmacists' expertise and complex commissioning frameworks.

- Community pharmacists should be introduced into the multidisciplinary team providing care to those with diabetes, but steps must first be made to promote their skill set and facilitate improved integration into existing care models.

Current research questions

- What are the strengths of community pharmacy in the delivery of clinical services?

- What have been the barriers to the wider integration of community pharmacy into existing healthcare models?

- What types of diabetes interventions have been delivered by community pharmacy and what have their outcomes been?

\section{Key references}

1. Deters MA, Laven A, Castejon A, Doucette WR, Ev LS, Krass I, et al. Effective Interventions for Diabetes Patients by Community Pharmacists: A Meta-analysis of Pharmaceutical Care Components. Annals of Pharmacotherapy. 2017;52(2):198-211.

2. Pousinho S, Morgado M, Falcão A, Alves G. Pharmacist Interventions in the Management of Type 2 Diabetes Mellitus: A Systematic Review of Randomized Controlled Trials. Journal of Managed Care \& Specialty Pharmacy. 2016;22(5):493-515.

3. Bukhsh A, Khan TM, Lee SWH, Lee L-H, Chan K-G, Goh B-H. Efficacy of Pharmacist Based Diabetes Educational Interventions on Clinical Outcomes of Adults With Type 2 Diabetes Mellitus: A Network Meta-Analysis. Front Pharmacol 2018;9:339.

4. van Eikenhorst $L$, Taxis $K$, van Dijk $L$, et al. Pharmacist-Led selfmanagementinterventions to improve diabetes outcomes. A systematic literature review and metaanalysis. Front Pharmacol 2017;8:891.

5. Hindi AMK, Schafheutle El, Jacobs S. Patient and public perspectives of community pharmacies in the United Kingdom: A systematic review. Health Expect 2018;21(2):409-28.

public awareness nationally was deemed important, but difficult when different areas provide different services. High quality experience and word of mouth were deemed the most effective ways of publicising services. The main values added included freeing up GP time and easier access for patients. To be effective, it was felt that all staff in a pharmacy should be trained on a service, which should be as specific as possible. It was expressed that GPs would need incentivising to refer to community pharmacy, and pharmacists remunerated for their time. To avoid duplication of work and to strengthen communication, shared care plans were recommended with read/write access to care

\section{Self assessment questions}

1. True or false. The public visits a pharmacist on average 20 times a year.

2. True or false, pharmacy interventions to date have been shown to deliver improved clinical outcomes.

3. True or false, the roles of community pharmacists are becoming more clinically focused with less of an emphasis on dispensing.

4. True or false for each of the following:

a. In the UK, to work as a pharmacist, an individual must have a Master in Pharmacy (MPharm).

b. Pharmacists undergo regular revalidation.

c. Pharmacists are less accessible than other outpatient healthcare set-ups.

5. Which of the following have been recognised as barriers to the wider integration of community pharmacy into the delivery of diabetes care (true/false)?

a. Too few pharmacists available to deliver diabetes care.

b. The skill set of pharmacists is poorly recognised.

c. Community pharmacy has complex contracts and commissioning routes which many don't understand.

d. Limited capability of available digital platforms.

e. Pharmacists are not keen on providing clinical services.

f. The public have not found community pharmacy interventions helpful in the past.

records. The importance of good safeguarding measures was stressed.

Evidence suggests that the public regard community pharmacy services as beneficial, but the clinical skills and capabilities of pharmacists are under-recognised both by patients and physicians. ${ }^{53}$ Practitioners report strong mutual respect for pharmacists as allied health professionals, but communication between them could be strengthened. ${ }^{55}$

\section{CONCLUSIONS AND SUMMARY}

Optimal diabetes care relies on a number of self-management practices. Pharmacists are ideally positioned to support and empower people with diabetes, helping them to maximise their healthcare potential.

Community pharmacy interventions in diabetes and other long-term conditions have proven to be feasible, acceptable to those taking part and capable of delivering improved health outcomes. It is important to ensure the fidelity of interventions before drawing conclusions from them. The active components of interventions can be challenging to decipher, but likely include person-centred approaches, goal setting, frequency of contact and availability of the pharmacist. The pharmacist being part of a multidisciplinary team and able to communicate with the participant's GP has helped streamline care and improve efficiency.

Due to their accessibility and flexibility, community pharmacies are well suited to support and reach out to those with diabetes, particularly those who may be most at need. An increased public awareness of the skill set and role pharmacists have to play is key to building public trust. It is hoped that with increasing recognition in government policy this will begin to be achieved. Measures also need to be put in place to facilitate improved communication and collaboration with other healthcare professionals and services, so that pharmacists can offer a synergistic role, becoming more fully integrated and equipped to facilitate a more responsive and flexible healthcare system. 


\section{Future work}

To facilitate reproducibility, interventions need to be well described. While the current evidence supports increased integration of pharmacists into the care pathway for those with diabetes, there have been no studies published specifically looking at the role of pharmacists in supporting those with diabetes who are struggling to engage with the services currently available to them or who are 'hardly reached'. Although not exhaustive, this may include people with diabetes who have not been attending their clinical appointments, those not taking their medications, or those with multiple hospital attendances or admissions relating to their diabetes. These individuals are arguably most vulnerable to the complications and health burden associated with diabetes, but potentially also have the most to gain from an alternative supplementary intervention or healthcare service. Although there are likely to be varying reasons and selfdeterminants underpinning the aforementioned behaviours, pharmacists are in a privileged position to help explore these and offer support to these individuals.

Future work will need to build public recognition of pharmacists, while also improving communication between them and other healthcare professionals in order to deliver continuity and best care.

\section{Twitter Sarah Brewster @drsarahbrewster}

Acknowledgements The authors thank Alison Freemantle, Professional Services Development Manager, Community Pharmacy South Central and Paula Sands, Research Engagement Librarian, University of Southampton.

\section{Collaborators Alison Freemantle.}

Contributors All authors (SB, RH, JP and HP) conceived the paper. SB wrote the search strategy which she discussed with a research engagement librarian. SB undertook the literature search and reviewed the titles and abstracts of the identified articles. SB wrote the first draft of the narrative literature review which was then discussed with all authors (RH, JP and HP). All authors (RH, JP and HP) provided critical feedback and helped shape the final manuscript which was approved by all authors ( $\mathrm{SB}, \mathrm{RH}, \mathrm{JP}$ and $\mathrm{HP}$ ) before submission.

Funding This study was funded by NHS England South (Wessex).

Competing interests None declared.

Patient consent for publication Not required.

Provenance and peer review Not commissioned; externally peer reviewed.

\section{ORCID iD}

Sarah Brewster http://orcid.org/0000-0001-8748-9037

\section{REFERENCES}

1 International Diabetes Federation. IDF diabetes atlas, 9th edition, 2019. Available: https://www.diabetesatlas.org/en/sections/worldwide-toll-of-diabetes.html

2 Diabetes UK. Diabetes prevalence 2017, 2017. Available: https://www. diabetes.org.uk/professionals/position-statements-reports/statistics/diabetesprevalence-2017 [Accessed Nov 2017].

3 Shrivastava SR, Shrivastava PS, Ramasamy J. Role of self-care in management of diabetes mellitus. J Diabetes Metab Disord 2013;12:14.

4 Public Health England. Pharmacy: a way forward for public health. opportunities for action through pharmacy for public health, 2017. Available: https://assets. publishing.service.gov.uk/government/uploads/system/uploads/attachment_data/file/ 643520/Pharmacy_a_way_forward_for_public_health.pdf

5 Royal Pharmaceutical Society. Frontline pharmacists: making a difference for people with longterm conditions, 2016.

6 International Pharmaceutical Federation. Pharmacy at a glance-2015-2017, 2017. Available: https://www.fip.org/files/fip/publications/2017-09-Pharmacy_at_a_Glance2015-2017.pdf [Accessed Sep 2017].

7 NHS England. How can your pharmacist help you? 2017. Available: https://www. england.nhs.uk/blog/how-can-your-pharmacist-help-you/ [Accessed 18 Oct 2017].

8 Royal Pharmaceutical Society. Using pharmacists to help improve care for people with type 2 diabetes, 2019. Available: https://www.rpharms.com/recognition/all-ourcampaigns/policy-a-z/diabetes/diabetes-policy [Accessed 10 Jul 2019].

9 International Pharmacetical Federation. Pharmacy vision: board of pharmaceutical practice future trends report, 2017. Available: https://www.fip.org/files/fip/BPP/Phar macy-Vision-BPP-Trends-Report.pdf
10 Pharmaceutical Services Negotiating Committee. Cpcf settlement: 2019/20 to 2023/ 24, 2019. Available: https://psnc.org.uk/contract-it/the-pharmacy-contract/cpcfsettlement-2019-20-to-2023-24/ [Accessed Jul 2019].

11 Nuremberg Institute for Market Decisions. Worldwide ranking: trust in professions, 2016. Available: https://www.nim.org/en/compact/focustopics/worldwide-rankingtrust-professions

12 Todd A, Copeland A, Husband A, et al. The positive pharmacy care law: an area-level analysis of the relationship between community pharmacy distribution, urbanity and social deprivation in England. BMJ Open 2014;4:e005764.

13 Todd A, Moore HJ, Husband AK, et al. Community pharmacy interventions for public health priorities: protocol for a systematic review of community pharmacy-delivered smoking, alcohol and weight management interventions. Syst Rev 2014;3:93.

14 Ali M, Schifano F, Robinson P, et al. Impact of community pharmacy diabetes monitoring and education programme on diabetes management: a randomized controlled study. Diabet Med 2012;29:e326-33.

15 Diabetes UK. Community pharmacists in the frontline, 2012. Available: https://dia betes-resources-production.s3-eu-west-1.amazonaws.com/diabetes-storage/migra tion/pdf/Diabetes\%2520Update\%2520-\%2520Community\%2520Pharmacists\%252 Oin\%2520the\%2520Front\%2520Line\%2520\%28December\%25202012\%29.pdf

16 NHS England. High value intervention in diabetes. Available: https://www. england.nhs.uk/rightcare/products/pathways/cvd-pathway/diabetes/

17 Pande S, Hiller JE, Nkansah N, et al. The effect of pharmacist-provided non-dispensing services on patient outcomes, health service utilisation and costs in low- and middleincome countries. Cochrane Database of Systematic Reviews 2013;2.

18 National Institute for Health and Care Excellence (NICE). Medicines adherence: involving patients in decisions about prescribed medicines and supporting adherence (CG76), 2009. Available: https://www.nice.org.uk/guidance/cg76

19 Holt RIG, Kalra S. A new dawn: improving the psychosocial management of diabetes. Indian J Endocrinol Metab 2013;17:95-9.

20 Dalton K, Byrne S. Role of the pharmacist in reducing healthcare costs: current insights Integr Pharm Res Pract 2017;6:37-46.

21 PricewaterhouseCoopers. The value of community pharmacy-summary report PSNC, 2016.

22 Hernandez-Tejada MA, Campbell JA, Walker RJ, et al. Diabetes empowerment, medication adherence and self-care behaviors in adults with type 2 diabetes. Diabetes Technol Ther 2012;14:630-4.

23 Brewster S, Bartholomew J, Holt RIG, et al. Non-attendance at diabetes outpatient appointments: a systematic review. Diabet Med 2020. doi:10.1111/dme.14241

24 Dokbua S, Dilokthornsakul P, Chaiyakunapruk N, et al. Effects of an asthma self-management support service provided by community pharmacists: a systematic review and meta-analysis. J Manag Care Spec Pharm 2018;24:1184-96.

25 Boots UK L, Rowlands pharmacy and well the community pharmacy future project, 2017. Available: http://www.communitypharmacyfuture.org.uk/

26 George J, McNamara K, Stewart K. The roles of community pharmacists in cardiovascular disease prevention and management. Australas Med J 2011;4:266-72.

27 Antoine S-L, Pieper D, Mathes T, et al. Improving the adherence of type 2 diabetes mellitus patients with pharmacy care: a systematic review of randomized controlled trials. BMC Endocr Disord 2014;14:53.

28 Collins C, Limone BL, Scholle JM, et al. Effect of pharmacist intervention on glycemic control in diabetes. Diabetes Res Clin Pract 2011;92:145-52.

29 Krass I, Schieback P, Dhippayom T. Adherence to diabetes medication: a systematic review. Diabet Med 2015;32:725-37.

30 Machado M, Bajcar J, Guzzo G C, et al. Sensitivity of patient outcomes to pharmacist interventions. Part I: Systematic Review and Meta-Analysis in Diabetes Management 2007:1569-82.

31 Santschi V, Chiolero A, Paradis G, et al. Pharmacist interventions to improve cardiovascular disease risk factors in diabetes. Diabetes Care 2012;35:2706.

32 Deters MA, Laven A, Castejon A, et al. Effective interventions for diabetes patients by community pharmacists: a meta-analysis of pharmaceutical care components. Ann Pharmacother 2018;52:198-211.

33 Sherifali D, Bai J-W, Kenny M, et al. Diabetes self-management programmes in older adults: a systematic review and meta-analysis. Diabet Med 2015;32:1404-14.

34 Babar ZU-D, Kousar R, Hasan SS, et al. Glycemic control through pharmaceutical care: a meta-analysis of randomized controlled trials. Journal of Pharmaceutical Health Services Research 2019;10:35-44.

35 Presley B, Groot W, Pavlova M. Pharmacy-led interventions to improve medication adherence among adults with diabetes: a systematic review and meta-analysis. Res Social Adm Pharm 2019;15:1057-67.

36 Pousinho S, Morgado M, Falcão A, et al. Pharmacist interventions in the management of type 2 diabetes mellitus: a systematic review of randomized controlled trials. J Manag Care Spec Pharm 2016;22:493-515.

37 Bukhsh A, Khan TM, Lee SWH, et al. Efficacy of pharmacist based diabetes educational interventions on clinical outcomes of adults with type 2 diabetes mellitus: a network meta-analysis. Front Pharmacol 2018;9:339.

38 Fazel MT, Bagalagel A, Lee JK, et al. Impact of diabetes care by pharmacists as part of health care team in ambulatory settings: a systematic review and meta-analysis. Ann Pharmacother 2017:51:890-907. 
39 van Eikenhorst L, Taxis K, van Dijk L, et al. Pharmacist-Led self-management interventions to improve diabetes outcomes. A systematic literature review and meta-analysis. Front Pharmacol 2017;8:891.

40 Bukhsh A, Tan XY, Chan KG, et al. Effectiveness of pharmacist-led educational interventions on self-care activities and glycemic control of type 2 diabetes patients: a systematic review and meta-analysis. Patient Prefer Adherence 2018:12:2457-74

41 Syarifuddin S, Nasution A, Dalimunthe A, et al. Impact of pharmacist intervention on improving the quality of life of patients with type 2 diabetes mellitus. Open Access Maced J Med Sci 2019;7:1401-5.

42 Soprovich AL, Sharma V, Tjosvold L, et al. Systematic review of community pharmacy-based and pharmacist-led foot care interventions for adults with type 2 diabetes. Can Pharm J 2019;152:109-16.

43 Withidpanyawong U, Lerkiatbundit S, Saengcharoen W. Family-Based intervention by pharmacists for type 2 diabetes: a randomised controlled trial. Patient Educ Couns 2019;102:85-92.

44 Obarcanin $E$, Krüger $M$, Müller $P$, et al. Pharmaceutical care of adolescents with diabetes mellitus type 1: the diadema study, a randomized controlled trial. Int J Clin Pharm 2015;37:790-8.

45 Deters MA, Läer S, Hasanbegović S, et al. Diabetes stewardship - pharmaceutical care of adolescents with type 1 diabetes mellitus provided by community pharmacists. Med Monatsschr Pharm 2016;39:477-82.

46 McDonnell ME. Telemedicine in complex diabetes management. Curr Diab Rep 2018;18:42

47 Nye AM. A clinical pharmacist in telehealth team care for rural patients with diabetes. N C Med J 2017;78:183-4.

48 Lauffenburger JC, Ghazinouri R, Jan S, et al. Impact of a novel pharmacist-delivered behavioral intervention for patients with poorly-controlled diabetes: the enhancing outcomes through goal assessment and generating engagement in diabetes mellitus (ENGAGE-DM) pragmatic randomized trial. PLoS One 2019;14:e0214754.

49 Lewey J, Wei W, Lauffenburger JC, et al. Targeted adherence intervention to reach glycemic control with insulin therapy for patients with diabetes (TARGIT-Diabetes): rationale and design of a pragmatic randomised clinical trial. BMJ Open 2017;7: e016551.
50 Pharmaceutical Services Negotiating Committee. PSNC Briefing 072/16: a summary of the Murray review of community pharmacy clinical services, 2016. Available: https://psnc.org.uk/wp-content/uploads/2013/04/PSNC-Briefing -072.16-A-summary-of-the-Murray-Review-of-Community-Pharmacy-ClinicalServices.pdf

51 The Kings Fund. Community pharmacy clinical services review, 2016. Available: https:// www.england.nhs.uk/commissioning/wp-content/uploads/sites/12/2016/12/commu nity-pharm-clncl-serv-rev.pdf

52 Almansour HA, Mekonnen AB, Aloudah NM, et al. Cardiovascular disease risk screening by pharmacists: a behavior change wheel guided qualitative analysis. Res Social Adm Pharm 2020;16:149-59.

53 Hindi AMK, Schafheutle El, Jacobs S. Patient and public perspectives of community pharmacies in the United Kingdom: a systematic review. Health Expect 2018;21:409-28

54 Hindi AMK, Schafheutle El, Jacobs S. Community pharmacy integration within the primary care pathway for people with long-term conditions: a focus group study of patients', pharmacists' and GPs' experiences and expectations. BMC Fam Pract 2019;20:26

55 Dähne A, Costa D, Krass I, et al. General practitioner-pharmacist collaboration in Germany: an explanatory model. Int J Clin Pharm 2019;41:939-49.

\section{Self assessment answers}

1. False. 16 times a year.

2. True.

3. True.

4. (a) true, (b) true, (c) false.

5. (a) false (b) true, (c) true, (d) true, (e) false, (f) false. 